\title{
FINITE ELEMENT ANALYSIS OF STRESS DISTRIBUTION IN WEAKENED TEETH RESTORED WITH DIFFERENT POST CORE MATERIALS
}

\author{
Doaa A. Elsharkawy* and Mohamed Salah Attia**
}

\begin{abstract}
Aim: This study aimed to investigate the stress patterns in weakened teeth restored with three different types of post core restorations under a vertical load using the finite element method. Methods: Four axisymmetric models were created by computer software to simulate the lower second permanent premolar in different situations. Situation 1: natural unrestored tooth, 2: weakened tooth restored with fiber reinforced composite post and core, 3: weakened tooth restored with gold alloy post and core, and 4: weakened tooth restored with zirconia post and core. The models included a post and core without a crown, gutta percha, resin cement and supporting structures. Models were considered isotropic, and exhibiting complete adhesion. A vertical static load of $40 \mathrm{~N} / \mathrm{mm}^{2}$ was applied to the occlusal surface. Von Mises tensile stresses were calculated in the model and presented in the form of a colored stress map. Results: Stress patterns in the fiber reinforced composite were closest to the stress pattern of natural tooth with most stresses found in the coronal area dissipating as they travel apically. Zirconia and gold post and cores had more stress concentration areas within the post and more apical than natural tooth or fiber reinforced composite. All post systems showed an area of stress concentration in dentin around the end of the post especially the zirconia post and core, however they were within the range of dentin tensile strength. Conclusion: zirconia posts are more likely to cause fracture in the root in weakened teeth when compared to fiber reinforced composite post and core. Fiber reinforced composite exhibits the closest biomechanical behavior to normal teeth.
\end{abstract}

KEYWORDS: weakened teeth, Finite element analysis, fiber reinforced composite

\section{INTRODUCTION}

Restoration of endodontically treated teeth is essential for ultimate survival of the tooth. The condition of the remaining tooth structure after the endodontic treatment is the main factor in choice of final restoration ${ }^{1}$. Teeth indicated for endodontic treatment have often lost a considerable amount of tooth structure due to caries. Endodontic treatment causes further loss of tooth structure due to endo procedures that weaken the tooth. Extensive loss of

\footnotetext{
* Lecturer of Operative Dentistry, Faculty of Dental Medicine For Girls, Alazhar University, Egypt
}

** Lecturer of Mechanical Engineering, Faculty of Engineering, Cairo University, Egypt 
tooth structure presents a problem in retention of coronal restoration as well as fracture proneness due to weakened state ${ }^{2}$. In many cases, posts combined with cores are the solution to the retention problem especially when most or all of the coronal portion is lost. These cores are advocated to be covered with a crown ${ }^{3}$. However, posts inserted in the root canal may create complications of their own as they may dramatically change the stress distribution in the tooth as well as hazards of post space preparation. Failures in post restored teeth are frequently attributed to fracture of the root with many catastrophic fractures in the root that necessitate extraction ${ }^{4}$.

The above factors are in some cases compounded by further weakening of teeth due to internal caries in root walls or overzealous radicular preparations and excessive coronal flaring rendering dentin walls very thin. In such cases the final choice of restoration presents a challenge to many clinicians ${ }^{5}$. Cases where root walls are too thin to support a ferrule preparation or receive a crown preparation are often deemed as non-restorable and recommended for extraction. However, extraction of a tooth is ideally replaced by a dental implant or less preferably a fixed bridge. Still, these options are not always available due to various reasons such as absence of suitable abutments or contra indications for an implant. Every effort should be done to save the weak teeth in this instance and try to find a solution to prolong its service in the oral cavity ${ }^{6}$.

The thinness of the dentin walls makes tensile stresses falling on them particularly precarious. Efforts done to try to reinforce the weak tooth have included the lining of the root with flowable composite for dentin reinforcement ${ }^{7}$. Bonding can also help in stress transfer and distribution in an effort to reinforce the tooth ${ }^{8}$. Material used for the restoration also plays a huge role in the pattern of stresses within the root. A post and core alone and bonded to the tooth structure may be the only available option in some clinical cases. Such cases would typically receive a custom made post and core. Materials available for this include ceramics, fiber reinforced composite and metallic post and cores like gold alloy ${ }^{9}$. Ceramic posts are stiff and strong and esthetic at the same time and allow for an esthetic overall restoration. Fiber reinforced post and cores have the advantage of bonding to composite resin and resin cement allowing for an all adhesive restoration. Studies have also shown that fractures with fiber posts produce more repairable failures than metal or ceramic ${ }^{10}$. Gold posts and cores have the advantage of being less stiff than nickel chromium, resist tarnish and corrosion, and can have a close fit on casting. All should to be bonded to the tooth using a resin cement for best outcomes ${ }^{11}$.

Several studies have compared stresses in an endodontically treated tooth using different restorative variables ${ }^{12,13}$. Studying the stress pattern in the tooth can help identify the areas most at risk. It can also help evaluate restoration designs and materials that will help give us the best stress distribution pattern that avoids or minimizes the risk of catastrophic fracture. Finite element analysis (FEA) is a useful tool to study the stresses in a tooth. It gives an idea about both the direction of the stresses and the magnitude ${ }^{14}$. FEA models can be 2D or 3D. $3 \mathrm{D}$ models are more accurate than $2 \mathrm{D}$ but are much more complicated and time consuming especially when it is possible to simulate $3 \mathrm{D}$ conditions. An axisymmetric model however is a $2 \mathrm{D}$ model that can give simulation of a $3 \mathrm{D}$ analysis as the $2 \mathrm{D}$ model is replicated by the computer on a $360^{\circ}$ angle around an axis. Axisymmetric models are useful for structures that have a general symmetry around a central axis and this was mostly the case with the second lower premolar. ${ }^{15}$.

This study focused on studying by FEA the stress pattern in weak endodontically treated teeth restored using three post core materials; gold alloy, zirconia and fiber reinforced composite and compared them to natural tooth structure. 


\section{MATERIALS AND METHODS}

Four finite element models were created to simulate the lower permanent second premolar. The models created were axisymmetric 2D models. The models were created using computer software (Cosmos Ver.2.9).

The model simulated a cylindrical block section of the mandible that included the root of a human second mandibular premolar and its supporting structures. The outer dimensions of the root, as well as the supporting structures were obtained from the literature ${ }^{16}$. The root length was $14 \mathrm{~mm}$ and its diameter at the cervical portion was $5.5 \mathrm{~mm}$. model $\mathrm{N} 1$ was assigned to a natural unrestored tooth, while $\mathrm{N} 2, \mathrm{~N} 3$ and N4 were assigned to different post core combinations. Fiber reinforced composite post and core was assigned to $\mathrm{N} 2$ model while gold alloy and zirconia were assigned to models N3 and N4 respectively (table 1). All posts and cores had the same dimensions but were given different mechanical properties to simulate different materials. The posts and cores were $15 \mathrm{~mm}$ in height and was inserted into the root to a depth of $10 \mathrm{~mm}$, leaving $4 \mathrm{~mm}$ of gutta percha. The core was $4 \mathrm{~mm}$ in height, and 4 $\mathrm{mm}$ in diameter. Resin cement thickness was given a value of $50 \mathrm{ums}$. The post diameter at the cervical portion was $4 \mathrm{~mm}$ to simulate excessive coronal flaring. This left only $0.75 \mathrm{~mm}$ of dentin wall thickness surrounding the post at the cervical level. Cementum was not modelled due to its closeness in mechanical properties to dentin (Fig.1). Periodontal ligament (PL), cortical bone (CB) and alveolar bone were also modeled. The geometry of the model was then copied into the software by defining different points by their distance from the $\mathrm{x}$ and $\mathrm{y}$ axis. 2 points would connect by means of a curve, and each closed section would be labeled a surface. Once the model dimensions and surfaces were created, meshing of the model was done to divide the model into 5282 nodes and 5088 elemnts.
TABLE (1) Simulated load situations

\begin{tabular}{|l|l|l|}
\hline Load situation & $\begin{array}{l}\text { Post and core } \\
\text { material }\end{array}$ & Load Direction \\
\hline N1 & None & Vertical \\
\hline N2 & $\begin{array}{l}\text { Fiber reinforced } \\
\text { composite (FRC) }\end{array}$ & Vertical \\
\hline N3 & Gold alloy & Vertical \\
\hline N4 & Zirconia & Vertical \\
\hline
\end{tabular}

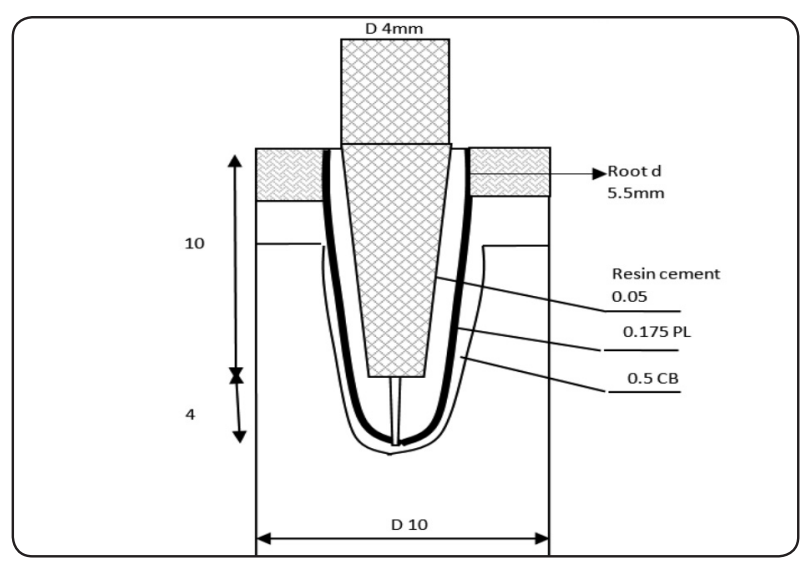

Fig. (1) Dimensions of models N2, N3 and N4

\section{Mechanical characteristics, boundary conditions and loading:}

Mechanical characteristics (Young's modulus and Poisson's ratio) were assigned to the different structures for calculation of Von Mises tensile stresses within the model (table 2). The model was considered homogenous, isotropic and exhibiting complete adhesion.

The model was set as bound to the $\mathrm{x}$ and $\mathrm{y}$ axis equally. A simulated vertical load of $500 \mathrm{~N}$ was applied perpendicular to the occlusal surface of the model. This load, uniformly distributed, resulted in a force of $40 \mathrm{~N} / \mathrm{mm}^{2}$. The load resulted in Von Mises tensile stresses calculated by the computer and were presented by a color scheme for better visualization of areas of high concentrations. 
TABLE (2) List of elastic constants of investigated materials

\begin{tabular}{|c|c|c|}
\hline Material & $\begin{array}{c}\text { Young's } \\
\text { modulus (GPa) }\end{array}$ & $\begin{array}{c}\text { Poisson's } \\
\text { ratio }\end{array}$ \\
\hline Human dentin & 18.6 & 0.31 \\
\hline Zirconia & 200 & 0.33 \\
\hline Fiber reinforced composite & 30 & 0.26 \\
\hline Resin cement & 8 & 0.3 \\
\hline Gold alloy & 96.6 & 0.35 \\
\hline Gutta percha & 0.00069 & 0.45 \\
\hline Gingiva & 0.003 & 0.45 \\
\hline Alveolar bone & 1.37 & 0.3 \\
\hline Cortical bone & 13.7 & 0.3 \\
\hline Periodontal ligament & 0.0689 & 0.45 \\
\hline
\end{tabular}

\section{RESULTS}

The finite element calculations were done and Von Mises stresses were calculated in the model. The stress distributions presented by colored models are shown in fig. 2. The stress distribution in an unrestored tooth showed stresses of range of 25-30 MPa in the crown dissipating as it travels towards the root. There is a small area of stress concentration at the cervical portion where the crown area meets the root as well as in the bone right below the root tip. Stresses in dentin are low especially in the apical two thirds. The FRC post showed the closest stress distribution to the natural tooth. It has a small area of stress concentration at the bone around the root tip. Dentin stresses are also increased apical to the end of the post, in the range of 28-32 MPa. The maximum stresses are present in the coronal portion in the range of $34-36 \mathrm{MPa}$ dissipating as they travel apically. The gold model showed higher stress concentrations mostly in the post itself and in the supporting structures at the root tip. Maximum stresses in the dentin are similar the other models in that they are concentrated apical to the post, but their values are slightly higher and bigger in area. The stresses within the post core itself is concentrated at the coronal third of the root and reached $44 \mathrm{MPa}$. The post dentin interface exhibited stresses that are in the range of $30-37 \mathrm{MPa}$. The zirconia model showed areas of stress concentration within the post core itself, at the tip of the root, at the tip of the post and in the dentin apical to the post. Dentin Von Mises stresses in this area in range of 30-35MPa and reached almost through the whole thickness of dentin. Within the post core system itself, there were two areas of high stress reaching 51 $\mathrm{MPa}$ in coronal and middle part of the root. Dentin on the side of the root received minimal Von Mises stresses with values of 6-8 MPa but the post dentin interface showed stresses of 37-39 MPa. Overall the fiber reinforced post core showed the closest resemblance to natural teeth and has minimal stress concentrations while the zirconia post core showed the highest stresses.

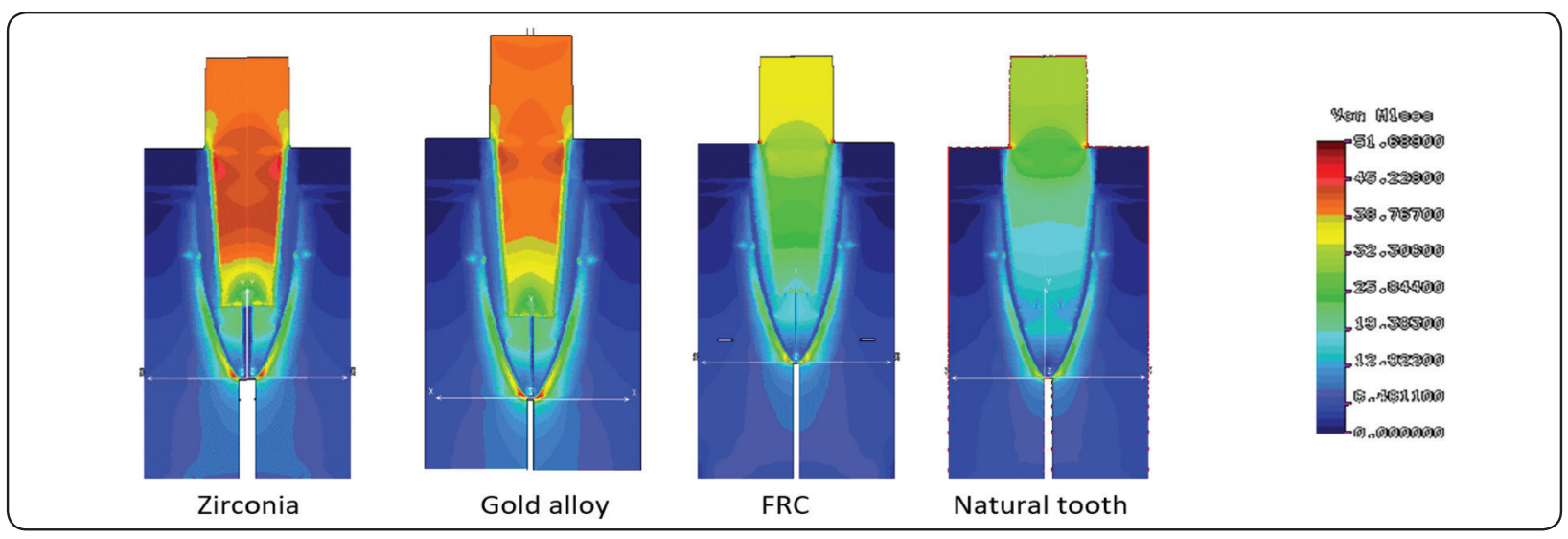

Fig. (2) Von Mises stress distribution in the different models under a vertical load 


\section{DISCUSSION}

The FEA method has several advantages for stress analysis. These include the elimination of errors that can occur in lab work as well as standardizing all the variables except that which are tested. It can also help identify the pattern or location of stresses in a structure rather than just give the maximum load it can endure which is the case in fracture resistance lab studies ${ }^{17}$. However, it has some disadvantages as it cannot replicate the complicated heterogeneous structure of biological tissue. Also it is difficult to simulate oral conditions that are complex and variable in character. However, it is useful for understanding the biomechanical behavior of different materials to help explain and understand lab or clinical data.

The axisymmetric model as the tooth studied was the second premolar which has a fairly round cross section of the root which made it possible to create. The Model consisted of post and core alone without a crown. The core did not exhibit occlusal anatomical features and was smaller than the diameter of the root. There were several reasons for this choice of model. One reason was to eliminate the factor of the crown anatomy and material, and study stresses if the forces are applied to the core material directly. This can indeed be the case in some otherwise non restorable teeth. Also, the reduced dimensions are to simulate a reduced occlusal table which can reduce the overall forces falling in the root in this case ${ }^{18}$. The lack of occlusal anatomy was for the convenience of stress distribution in an axisymmetric model that evenly distributes the forces across the surface.

Stress analysis showed FRC post and core to have the most similar stress pattern to natural tooth. This result is similar to other studies that have shown fiber posts in non-weakened teeth to exhibit normal tooth like stresses ${ }^{19,20}$. This may be due to similar modulus of elasticity which allowed the post to transmit the stresses like normal dentin and avoid areas of extreme stress concentration ${ }^{21}$. It was noted that the maximum stresses were more towards the core and crown suggesting more favorable or repairable fractures. Based on this pattern, A failure in fiber reinforced post and core restored tooth could be due to core fracture at the cervical region, or debonding more than root fracture in apical region $^{22}$.

The gold alloy model showed more stress in the post itself similar to zirconia. For zirconia especially, area of stresses apical to the post is dangerously encompassing most of the dentin thickness. Even though the stress values were below the dentin strength limit, dentin integrity is challenged especially that dentin is thin in this area. There is serious danger of dentin cracks or fracture in apical area with cyclic loading and possible crack propagation $^{23}$. It is noted that the dentin adjacent to the post in the midroot exhibited low stresses due to the post absorbing most of the high stresses within it. The large post diameter helped in distributing the stress within it when compared to thinner posts. However, the ability of the post to support the root and absorb the stresses rather than directly transmit them to the dentin is completely dependable on the bond between the tooth and the post. Non bonded posts exhibit extremely higher stresses in dentin ${ }^{8}$. This bond is in jeopardy as the stresses at the postcement-dentin interface are approaching $30 \mathrm{MPa}$ in some areas which is higher than that of most dentin bonding agents ${ }^{24}$. A possible loss of bond at this area with possible transmission of these high forces to the dentin with such thin walls could lead to root fracture in the apical third. Gold same but to a lesser degree. Zirconia is frequently advocated due to excellent strength, esthetics and wear resistance but stress areas make it dangerous to use in weak $\operatorname{roots}^{25}$.

Vertical load was used in this study thus giving most of the stresses in the area beneath the post and the root. Oblique loads could give a yet more different distribution which might be hazardous to the thin dentin section. 


\section{CONCLUSION}

Weak roots may benefit from bonded restorations for reinforcement, but stiff posts such as zirconia can cause stresses in an area of root that can cause catastrophic root fracture. Fiber reinforced composite seems to be the safest choice in terms of stresses for restoration of weakened teeth.

\section{REFERENCES}

1 Tang W, Wu Y, Smales RJ. Identifying and reducing risks for potential fractures in endodontically treated teeth. J Endod 2010;36:609-617

2 Sorrentino R, Di Mauro MI, Ferrari M, Leone R, Zarone F. Complications of endodontically treated teeth restored with fiber posts and single crowns or fixed dental prostheses-a systematic review. Clin Oral Investig 2016 20:14491457

3 Veríssimo C, Simamoto Júnior PC, Soares CJ, Noritomi PY, Santos-Filho PC. Effect of the crown, post, and remaining coronal dentin on the biomechanical behavior of endodontically treated maxillary central incisors. J Prosthet Dent 2014;111:234-246

4 Pierrisnard L, Bohin F, Renault P, Barquins M. Coronoradicular reconstruction of pulpless teeth: a mechanical study using finite element analysis. J Prosthet Dent 2002;88:442-448. 18

5 Mariana Carolina de Lara Ferro, Vivian Colucci, Artur Gaiotto Marques, et al. Fracture Strength of Weakened Anterior Teeth Associated to Different Reconstructive Techniques. Brazilian Dental Journal. 2016, Vol.27, 556-561.

6 VF Wandscher, CD Bergoli, IF Limberger, et al. Preliminary Results of the Survival and Fracture Load of Roots Restored With Intracanal Posts: Weakened vs Nonweakened Roots. Operative Dentistry. 2014, Vol.39, No.5, p.541.-555

7 Seghi RR, Nasrin S, Darney J and Katsube N. Root fortification. Pediatr.dent. 2013; 35:153-9

8 Asmussen E., Peutzfelt A and Sahafi A. fininte element analysis of stresses in endodontically treated, dowel restored teeth. J prosthet. Dent. 2005; 94:321-9

9 Silva NR, Castro CG, Santos-Filho PC, Silva GR, Campos $\mathrm{RE}$, Soares PV, et al.. Influence of different post design and composition on stress distribution in maxillary cen- tral incisor: Finite element analysis. Indian J Dent Res 2009;20:153-158

10 Figueiredo FE, Martins-Filho PR, Faria-E-Silva AL. Do metal postretained restorations result in more root fractures than fiber postretained restorations? A systematic review and meta-analysis. J Endod 2015;41:309-316.

11 Lanza A, Aversa R, Rengo S, Apicella D, Apicella A. 2005. 3D FEA of cemented steel, glass and carbon posts in a maxillary incisor. Dent Mater 2005;21:709-715

12 Chuang SF, Yaman P, Herrero A, Dennison JB, Chang $\mathrm{CH}$. Influence of post material and length on endodontically treated incisors: an in vitro and finite element study. J Prosthet Dent 2010;104:379-388

13 Ukon S, Moroi H, Okimoto K, Fujita M, Ishikawa M, Terada $\mathrm{Y}$, et al. Influence of different elastic moduli of dowel and core on stress distribution in root. Dent Mater J 2000;19:50-64

14 Sorrentino R, Aversa R, Ferro V, Auriemma T, Zarone F, Ferrari M, et al. 2007. Three-dimensional finite element analysis of strain and stress distributions in endodontically treated maxillary central incisors restored with different post, core and crown materials. Dent Mat 2007;23:983993

15 Holmes D.C., Diaz-ArnoldA.M., Leary J.M.: Influence of post dimension on stress distribution in dentin. Prosthet. Dent. 1996;75: 140-7

16 Major M. Ash Wheeler's Dental Anatomy, Physiology and Occlusion - Elsevier eBook on VitalSource, 10th Editionby Major M. Ash

17 Megahed M.M., Saleh C.A.R., AttiaM.S.: Mechanics of Elasticity and Plasticity. A graduate-level course at the department of Mechanical Design and Production, 2006,Faculty of Engineering,Cairo University

18 V. Rangarajan, P. B. Yogesh, B. Gajapathi, M. Mohamed Ibrahim, R. Ganesh Kumar, and Murali Karthik Concepts of occlusion in prosthodontics: A literature review, part II J Indian Prosthodont Soc. 2016 Jan-Mar; 16(1): 8-14.

19 Santos AF, Meira JB, Tanaka CB, Xavier TA, Ballester RY, Lima RG, et al.. Can fiber posts increase root stresses and reduce fracture? J Dent Res 2010;89,587-591.

20 Sorrentino R, Di Mauro MI, Ferrari M, Leone R, Zarone F. Complications of endodontically treated teeth restored with fiber posts and single crowns or fixed dental prostheses-a systematic review. Clin Oral Investig 2016 20:14491457 
21 VF Wandscher, CD Bergoli, IF Limberger, TP Cenci, P Baldissara, and LF Valandro Fractographical Analysis and Biomechanical Considerations of a Tooth Restored With Intracanal Fiber Post: Report of the Fracture and Importance of the Fiber Arrangements. Operative Dentistry: 2016, Vol. 41: E149-E158.

22 Rasimick BJ1, Wan J, Musikant BL, Deutsch AS J Prosthodont. A review of failure modes in teeth restored with adhesively luted endodontic dowels. J Prosthodont 2010; 19: 639-46

23 Gomes ÉA, Gueleri DB, da Silva SR, Ribeiro RF, SilvaSousa YT. Threedimensional finite element analysis of endodontically treated teeth with weakened radicular walls restored with different protocols. J Prosthet Dent 2015;114:383-389

24 Eshrak Sofan, Afrah Sofan, Gaspare Palaia, Gianluca Tenore, Umberto Romeo, Guido Migliau Classification review of dental adhesive systems: from the IV generation to the universal type Ann Stomatol (Roma) 2017 JanMar; 8(1): 1-17

25 Soares PV, et al.. Influence of different post design and composition on stress distribution in maxillary central incisor: Finite element analysis. Indian J Dent Res 2009;20:153-158 